\title{
Jornal Escolar Utilizando o Linux Educacional - Um Relato de Experiência
}

\author{
Jonas Pereira Veras, Paulo Afonso Júnior, Heitor Costa \\ Departamento de Ciência da Computação - Universidade Federal de Lavras - MG - Brasil \\ jonas_veras_soad@yahoo.com.br, \{pauloa.junior, heitor\}@dcc.ufla.br
}

Resumo. Com o surgimento de novas tecnologias, a maneira como o aluno adquire e produz o conhecimento vem se modificando e até a produção do antigo jornal escolar se modificou com estes avanços tecnológicos. Jornalismo e Educação vêm se adaptando e se utilizando de novas ferramentas para aperfeiçoar o processo de comunicação e de ensinoaprendizagem. Durante o processo de letramento os alunos precisam compreender a função social da língua, conhecer e também produzir diversos gêneros textuais, entre eles, o texto noticioso ou jornalístico. Este trabalho tem como objetivo apresentar o gênero jornalístico aos alunos e incentivar a produção de textos através de um jornal escolar produzido com o suporte de aplicativos do sistema operacional Linux Educacional.

\begin{abstract}
With the emergence of new technologies, the way the student acquires, produces knowledge has been changing, and even the production of the old school newspaper has changed with these technological advances. Journalism and Education have been adapting and using new tools to improve the communication and teaching-learning process. During the process of literacy, students need to understand the social function of the language, to know and to produce diverse textual genres, among them, the news or journalistic text. This work aims to present the journalistic genre to the students and encourage the production of texts through a school newspaper produced with the support of applications of the Linux Educational operating system.
\end{abstract}

\section{Introdução}

As novas tecnologias têm produzido diversas mudanças comportamentais na sociedade e essas modificações aplicam-se em duas instituições importantíssimas: a Escola e a Imprensa. Embora a educação e o jornalismo ainda mantenham o seu objetivo original, eles utilizam de novos meios e linguagens para atingir tais objetivos.

\footnotetext{
Cada época tem uma linguagem e utensílios que lhe são próprios. Os nossos avôs utilizavam manuscritos e a pena de pato numa escola onde a autoridade do professor se manifestava através das reguadas e pelas orelhas de burro [Freinet, 1974].
}

A escola contemporânea enfrenta o grave problema do analfabetismo funcional, no qual as pessoas conseguem ler, porém não compreendem o que está escrito. Para combater o analfabetismo funcional, tem-se utilizado o método do Letramento. $\mathrm{O}$ letramento é um processo complexo e dinâmico de ensino-aprendizagem, constituído de interações de diferentes tipos entre sujeitos, linguagens e discursos; interações mediadas por redes estruturadas e estruturantes de objetos culturais e tecnologias, ou seja, por objetos e tecnologias que direcionam e organizam o andamento do processo e são 
VIII Congresso Brasileiro de Informática na Educação (CBIE 2019)

Anais do XXV Workshop de Informática na Escola (WIE 2019)

redirecionadas por ele [Signorini, 2007].Durante o processo de letramento, é necessário apresentar diversas linguagens e gêneros textuais e diversificar ao máximo as estruturas textuais e ferramentas linguísticas.

Quanto mais diversificada a experiência de leitura dos alunos, quanto mais familiaridade eles tiverem com textos narrativos, expositivos, descritivos, mais conhecida será a estrutura desse texto e mais fácil a percepção das relações entre a informação veiculada no texto e a sua estrutura [Kleiman, 1993].

Entre as linguagens e os gêneros que podem ser apresentados aos alunos, está o gênero jornalístico por meio de narrativas sobre a realidade cotidiana dos estudantes que podem produzir conteúdo e sentirem-se estimulados a ler e escrever.

A criança sente a necessidade de escrever, exatamente porque sabe que o seu texto, se for escolhido, será publicado no jornal escolar e lido, portanto, pelos seus pais e pelos correspondentes; por isso sente a necessidade de expandir o seu pensamento por meio de uma forma e de uma expressão que constituem a sua exaltação [Freinet, 1974].

Em tempos atuais, nos quais as pessoas querem se expressar e apresentar suas insatisfações e reivindicações, o jornalismo comunitário assume o papel de porta-voz da população e a escola como parte importante da comunidade também pode se expressar, comunicar-se e dar voz aos alunos por meio de um jornal escolar.

O jornal escolar é um espaço de aprendizagem de participação; não apenas no projeto comum da produção do próprio jornal, mas na vida da escola e da comunidade [Faria, 2002].

O primeiro jornal escolar surgiu na Bélgica após a Primeira Guerra Mundial, a publicação chamava-se Correio da Escola produzido e impresso na Escola Decroly [Freinet, 1974]. Antes disso, alguns folhetins foram produzidos por estudantes, professores e pais de alunos, entretanto eles não tinham finalidade pedagógica; em sua maioria, esses folhetins eram manifestos com reivindicações e críticas ao sistema escolar, porém eles não eram considerados jornais escolares [Freinet, 1974].

Dos primórdios do jornalismo escolar no início do século XX na Escola Decroly até os tempos atuais, diversas ferramentas foram utilizadas, por exemplo, manuscritos, mimeografados, fotocopiados, impressos e mídias sociais. Apesar dos avanços tecnológicos, o jornalismo escolar tem finalidades pedagógicas. Se antigamente os alunos utilizavam o texto escrito, o mimeógrafo e as máquinas de datilografar, hoje os alunos podem produzir seus textos utilizando computadores, tablets e celulares e divulgá-los em blogs, sites ou imprimi-los em pequenas gráficas ou em impressoras domésticas.

Para produzir um jornal, independentemente da mídia, é necessário partir do princípio que, em geral, o texto jornalístico deve responder a seis questões fundamentais (traduzidas dos manuais norte-americanos) [Rossi, 2017]: Quem? O que? Onde? Quando? Como? e Por que?. No jornalismo diário, essas questões são respondidas no primeiro parágrafo do texto. A esse parágrafo, dá-se o nome de Lead ou pirâmide invertida, pois as informações mais importantes se encontram no início do texto e as menos importantes no final.

Uma ferramenta gratuita para produção de conteúdo (seja ele jornalístico ou não) é o software LibreOffice Writer, disponível no sistema Operacional Linux Educacional que permite a produção, edição, diagramação e impressão de diversos tipos de documentos. 
Neste trabalho, o objetivo é utilizar a linguagem jornalística usando um jornal mural como ferramenta no ensino da língua portuguesa, além de fortalecer os vínculos entre os alunos e a comunidade escolar e estimular a curiosidade, o senso crítico e a leitura utilizando aplicativos do Sistema operacional Linux Educacional. O jornal mural é uma ferramenta importante no setor corporativo, entretanto esse meio de comunicação pode ser utilizado nas escolas por conta do seu baixo custo e fácil implementação [França, 1988].

Entre os multimeios da comunicação empresarial, o "Jornal
Mural" constitui uma das formas mais rápidas e eficientes de
comunicação com os empregados. Instrumento dinâmico abre
espaço para um rol de informações jamais focalizadas por
outros veículos empresariais, caracterizando-se principalmente
por ser um veículo diário e imediato da comunicação da
empresa com seus funcionários e de baixo custo [França,
1988].

Há diversos artigos e experimentos acadêmicos que utilizam o jornalismo escolar como objeto de estudo, porém, durante o levantamento bibliográfico para a produção desta pesquisa não foi encontrado nenhum trabalho que contemple a utilização do Linux educacional ou softwares livres.

O artigo está organizado da seguinte forma. Na Seção 2, é apresentada a fundamentação teórica. Na Seção 3, é explicado o design da pesquisa. Na Seção 4, é discutida a aplicação e a realização das atividades em sala de aula. $\mathrm{Na}$ Seção 5, são apresentados os resultados da análise a respeito da aplicação da atividade com dados oriundos da participação dos alunos nas atividades e de uma entrevista com o professor. Na seção 6, são apresentadas as considerações finais deste trabalho.

\section{Fundamentação Teórica}

Foi realizada a leitura prévia de alguns autores dos campos da comunicação e da educação, o principal autor utilizado foi Freinet que disserta sobre o jornal escolar, sua história, importância, utilização e produção [Freinet, 1977]. Faria também ensina como produzir um jornal escolar [Faria, 2002], França enaltece a praticidade do jornal mural [França, 1988]. Com relação ao letramento, Kleiman e Signorini ressaltam a importância da diversidade textual no processo de letramento [Kleiman, 1993; Signorini, 2007]. Lemos apresenta as características e funções do Linux Educacional [Lemos, 2010]. Rossi explica o que é o jornalismo, o que é um lead e propõe reflexões sobre a profissão [Rossi, 2017]. Com esses autores, é perceptível a necessidade da diversificação textual no processo de letramento, a importância do jornal escolar como gênero textual na formação de novos leitores e escritores e as vantagens da utilização do sistema operacional Linux educacional.

Utilizando o método fenomenológico, neste artigo, é apresentada a experiência tal qual ela foi feita, retratando a realidade do planejamento, da elaboração, da produção e da aplicação e avaliação dos materiais e do processo de ensino-aprendizagem. $O$ resultado foi avaliado de maneira qualitativa analisando o desempenho dos alunos na execução das atividades aplicadas. 
VIII Congresso Brasileiro de Informática na Educação (CBIE 2019)

Anais do XXV Workshop de Informática na Escola (WIE 2019)

\section{Design de Pesquisa}

Na Figura 1, as cinco primeiras etapas apresentam a fase inicial do projeto. A escolha do tema é o ponto de partida no qual ocorre a investigação de problemas e de possíveis soluções (Etapa 1). O levantamento bibliográfico é a pesquisa na literatura acadêmica de trabalhos que dão embasamento ao artigo (Etapa 2). Na Etapa 3, há o planejamento e a elaboração do cronograma e das atividades com a determinação dos prazos e das metas para a elaboração da atividade. A avaliação e a sequência pedagógica são o momento de organizar as ideias obtidas no planejamento e colocá-las no papel para avaliar a viabilidade do projeto e os recursos necessários para a aplicação das atividades (Etapa 4). A produção de conteúdo é o momento no qual as atividades são elaboradas e é produzido o conteúdo a ser trabalhado em sala de aula (Etapa 5). A aplicação das atividades e avaliação em sala de aula é a etapa na qual os alunos assumem o protagonismo, pois a sequência didática é colocada em prática e as atividades elaboradas anteriormente são aplicadas e avaliadas individual e coletivamente em sala de aula (Etapa 6). O desempenho dos alunos é registrado durante a aplicação das atividades (Etapa 7) e, posteriormente, esses dados são coletados para análise dos resultados e avaliação do desempenho e da realização dos objetivos propostos durante a fase inicial do projeto (Etapa 8).

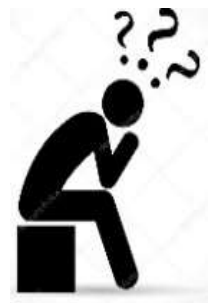

Etapa 1. Escolha do Tema

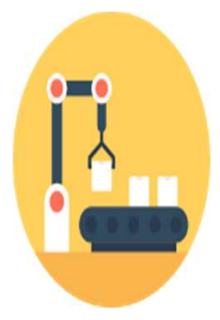

Etapa 5. Produção de Conteúdo e Materiais
Figura 1-Design da Pesquisa

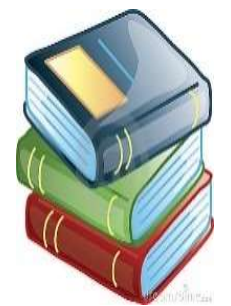

Etapa 2. Levantamento Bibliográfico

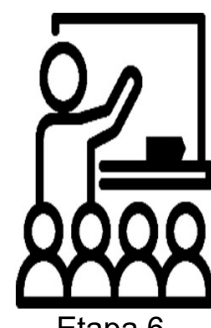

Aplicação das Atividades e Avaliação em Sala de Aula

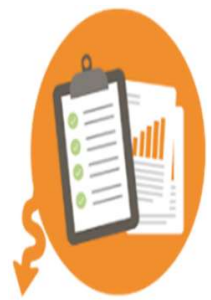

Etapa 3. Planejamento e Elaboração do Cronograma

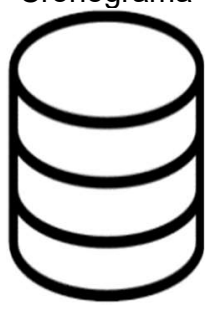

Etapa 7. Coleta de Dados

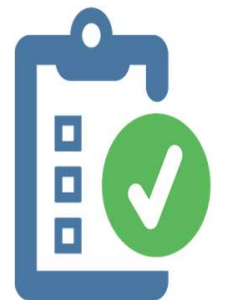

Etapa 4. Elaboração e Avaliação da Sequência Didática

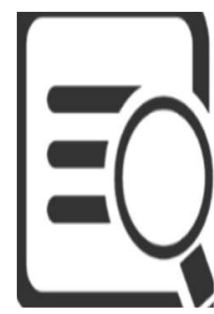

Etapa 8. Análise dos Resultados

\section{Aplicação}

Nesta seção, é apresentada a elaboração da sequência didática, desde a escolha do tema até a sua formalização, passando pela definição do público-alvo, objetivos, atividades e linhas estratégicas para verificar a viabilidade e os recursos necessários para a aplicação das atividades. 
VIII Congresso Brasileiro de Informática na Educação (CBIE 2019)

Anais do XXV Workshop de Informática na Escola (WIE 2019)

\subsection{Planejamento}

A escolha do tema foi baseada em duas áreas de estudo: i) Educação; e ii) Comunicação. Após algumas pesquisas iniciais, foi verificada a importância do jornal escolar no ensino da língua portuguesa e na formação cidadão dos alunos. Com a escolha do tema definida, foi iniciada pesquisa bibliográfica que envolvia a história do jornalismo escolar, a sua importância e a utilização do jornalismo na formação de leitores e escritores. Depois do estudo de diversos livros e artigos sobre o jornalismo escolar, foram iniciados o planejamento e a elaboração das atividades, definidos os objetivos, o público alvo, os recursos, o conteúdo, as linhas estratégicas e as atividades e elaborada a seguinte sequência didática:

- Público-alvo: Alunos do $5^{\circ}$ ano da Rede pública de Ensino;

- Objetivos Gerais: Apresentar novos gêneros textuais e linguagens;

- Objetivos Específicos: Ensinar a linguagem jornalística aos alunos e estimular a produção textual.

- Analisar Situação Atual: Os alunos têm algumas dificuldades com a disciplina de língua portuguesa como produção textual e identificação de gêneros literários e pouca familiaridade com o gênero jornalístico. Além disso, eles apresentavam problemas com o trabalho em equipe e não participam ativamente na vida cotidiana da escola e da comunidade;

- Definir Conteúdo: Utilização de jornais impressos, revistas, vídeos com reportagens e documentários, websites jornalísticos e um manual produzido pelo professor com textos sobre a atividade e as técnicas jornalísticas para os alunos poderem familiarizar-se com o jornalismo;

- Esboçar Atividades:

Atividade 01. Consiste na leitura de jornais e de revistas para os alunos identificarem elementos que diferenciam o texto jornalístico dos outros gêneros textuais;

Atividade 02. Os alunos debateram com o professor a respeito da importância do jornalismo para a construção de uma sociedade livre e democrática;

Atividade 03. Após uma aula teórica a respeito do conceito do Lead e da Pirâmide Invertida, os alunos produziram um Lead sobre uma notícia que tenham lido, ouvido ou assistido recentemente;

Atividade 04. Os alunos sabem a importância do jornalismo e as técnicas básicas, este foi o momento em que eles produziram um texto sobre algum acontecimento relacionado à escola ou à comunidade;

Atividade 05. Após uma aula sobre técnicas de entrevista, os alunos entrevistaram funcionários da escola e produziram um texto corrido ou um bate-bola com perguntas e respostas;

Atividade 06. Após uma aula sobre fotojornalismo e a exibição de fotos marcantes e premiadas do jornalismo, com o auxílio de câmeras de celular, os alunos fotografaram cenas cotidianas da escola;

Atividade 07. Após conhecerem os conceitos, a linguagem, a rotina e a produção jornalística, os alunos organizaram seus textos, fotos e entrevistas para produzir um jornal impresso e colado no mural da escola.

- Recursos Necessários: Para a atividade ser realizada com sucesso, foi necessária a utilização do laboratório de informática na escola, com computadores com Linux Educacional, internet, aplicativos de edição de fotos, aplicativos de edição de texto como o LibreOffice instalados, um Datashow para auxiliar a aula e caixinhas de som, além de revistas jornais e textos impressos com textos relacionados à atividade 
VIII Congresso Brasileiro de Informática na Educação (CBIE 2019)

Anais do XXV Workshop de Informática na Escola (WIE 2019)

jornalística;

- Linhas Estratégicas de Desenvolvimento: O professor produziu conteúdo em casa, juntou jornais e revistas, escolheu os vídeos exibidos, imprimiu os textos utilizados em sala de aula, verificou a sala de informática se o equipamento está em funcionamento e se os aplicativos necessários estão instalados;

- Linhas Estratégicas de Aplicação e Avaliação: No início de cada aula, o professor trabalhou e explicou os conceitos do jornalismo, a história, a linguagem e a produção. Todas as aulas iniciaram com a explicação do professor, a utilização de textos e vídeos e, em seguida, os alunos realizaram as atividades propostas;

- Formalizar Planejamento: O planejamento foi formalizado por meio de planos de aula e sequências didáticas, o tempo estimado para a atividade foi 06 aulas. Os softwares utilizados na produção e na aplicação das atividades foram avaliados utilizando o método TICESE (Técnica de Inspeção de Conformidade ergonômica de Software Educacional) [Pinto; Cybis, 2000].

\begin{abstract}
A técnica é formada por um conjunto específico de critérios de análise e tem seu suporte teórico nas ciências cognitivas, ergonomia de software, psicologia da aprendizagem e pedagogia. Aos critérios está associado um conjunto de questões que visa orientar o(s) avaliador(s) na difícil tarefa de inspecionar as qualidades ergonômico/pedagógicas do software educacional [Pinto; Cybis, 2000].
\end{abstract}

\title{
4.2 Aplicação e Avaliação das Atividades
}

Nesta seção, é apresentada a parte prática da sequência didática, após o planejamento e a elaboração das aulas. Esse é o momento no qual os alunos tiveram contato com os conteúdos e as atividades.

\subsubsection{Aula 01}

Reuniu-se 28 alunos na sala de informática, cada computador utilizado por grupos de 03 integrantes, tendo um grupo com 04 integrantes. Cada grupo recebeu um manual de jornalismo e um recorte de jornal com uma notícia da editoria de cidades (cotidiano). A Atividade 01 iniciou. Foi solicitado a cada grupo a leitura dos textos; após 10 minutos, foi perguntado aos alunos "quais eram as diferenças entre aqueles textos noticiosos e os textos que eles liam habitualmente na escola?". Um aluno afirmou que a diferença era que aqueles textos falavam a verdade enquanto os outros textos eram de histórias fantasiosas. Ele foi contestado: "Mas os textos que aparecem nos livros de história, de matemática, de ciências, etc., também possuem textos que falam a verdade". Outro aluno argumentou: "Mas esse texto do jornal fala de coisas que aconteceram recentemente" e outro aluno completou "o texto do jornal fala de coisas que acontecem perto da gente, por exemplo, uma campanha de vacinação, ou um acidente de carro". Após ouvir as opiniões dos alunos, foram explicadas as diferenças linguísticas e estruturais do texto jornalístico.

Na mesma aula, ocorreu a Atividade 02. Foi explicada a história do jornalismo, da imprensa e do papel do jornalismo na comunidade, sendo esclarecidas dúvidas dos alunos e exibição de um vídeo sobre o jornalismo com a utilização do aplicativo Mozilla Firefox ${ }^{1}$ para abrir o site Youtube $^{2}$. Em seguida, ocorreu um debate sobre a importância e a necessidade do jornalismo. Um aluno afirmou que "a importância do

${ }^{1}$ https://www.mozilla.org/pt-BR/firefox/new/

${ }^{2}$ https://www.youtube.com/ 
VIII Congresso Brasileiro de Informática na Educação (CBIE 2019)

Anais do XXV Workshop de Informática na Escola (WIE 2019)

jornalismo é manter as pessoas informadas"; outro acrescentou "o jornalismo ajuda as pessoas a saberem o que está acontecendo".

\subsubsection{Aula 02}

A aula contou com a presença de 29 alunos. Divididos em nove grupos de 03 integrantes, tendo um grupo com 02 integrantes. Novamente, os alunos abriram o arquivo de texto no LibreOffice Writer. O conteúdo da aula foi o conceito do Lead, uma técnica jornalística que responde seis perguntas (Quem? O que? Onde? Quando? Como? e Por quê?) e ajuda a estruturar o texto colocando as informações principais sempre no primeiro parágrafo.

A organização do Lead também pode auxiliar no trabalho com outros tipos de texto, incluindo-se, por exemplo, os textos mais técnicos, como requerimentos, ofícios, memorandos, entre outros [Faria, 2002].

Para facilitar a compreensão dos alunos, foi elaborada a Tabela 1 no LibreOffice Writer com as seis perguntas respondidas juntamente com o Lead produzido e exibido no datashow. Após a explicação sobre o Lead, foi iniciada a Atividade 03, solicitando aos alunos que "abrissem" o LibreOffice Writer e produzissem um Lead baseado em qualquer notícia recente que tenham recebido, seja por rádio, televisão, jornal, revista ou de coisas que tenham vivenciado. Cada aluno teve 10 minutos para utilizar o computador.

Tabela 1 - Modelo para Elaboração de Lead

\begin{tabular}{|l|l|}
\hline Quem? & O São Paulo \\
\hline O que? & Foi derrotado \\
\hline Onde? & No Maracanã \\
\hline Quando? & No domingo \\
\hline Como? & Por 2 a 1 para o Flamengo \\
\hline Por quê? & Jogou mal \\
\hline Lead & $\begin{array}{l}\text { "O São Paulo jogou mal e foi derrotado pelo Flamengo por de } 2 \text { a } 1 \text { no } \\
\text { Maracanã." }\end{array}$ \\
\hline
\end{tabular}

\subsubsection{Aula 03}

Quando os alunos chegaram à sala de informática, os computadores estavam ligados e com o aplicativo LibreOffice Writer aberto com um documento em branco para a aplicação da Atividade 04. Cada aluno teve 20 minutos para produzir um texto jornalístico curto de até três parágrafos baseado em alguma experiência que tenham vivenciado na escola ou na comunidade utilizando a técnica Lead no primeiro e utilizando os outros dois parágrafos para detalhar melhor o relato. A atividade foi realizada sem problemas.

\subsubsection{Aula 04}

A aula teve início com explicação de 20 minutos sobre técnicas de entrevista. Foi explicada a diferença entre perguntas fechadas e perguntas abertas e as técnicas para produzir um texto com entrevistas, seja ele um texto corrido no qual o autor produz um texto narrativo com trechos da entrevista ou o texto "pingue-pongue" no qual o jornalista faz uma pequena introdução e, em seguida, coloca as perguntas e as respostas do entrevistado da maneira exata como foram feitas. Após a explicação, teve início a 
VIII Congresso Brasileiro de Informática na Educação (CBIE 2019)

Anais do XXV Workshop de Informática na Escola (WIE 2019)

Atividade 05. Os alunos dividiram-se em grupos de 03 integrantes e deveriam escolher um funcionário da escola para uma entrevista de 10 perguntas. Dentre os colaboradores escolhidos pelos alunos, estava a diretora, a secretária, o coordenador, os professores, a merendeira, a faxineira e o inspetor. Cabe ressaltar que todos eles foram extremamente prestativos com os alunos. Ao final da aula, foi solicitado aos alunos que produzissem seus textos na sala de informática fora do horário de aula e salvassem para posterior avaliação.

\subsubsection{Aula 05}

Antes de iniciar a aula, foi verificado se os grupos haviam produzido o texto com a entrevista da aula anterior. Dando continuidade à aula, foi explicado o que é fotojornalismo e algumas imagens icônicas do fotojornalismo foram apresentado utilizando o datashow. Foi mostrado aos alunos que, por trás daquelas imagens, havia um contexto e diversas histórias, explicando que no jornalismo a foto pode ter a finalidade de ilustrar um texto ou a imagem por si só pode trazer diversas informações e informar mais que um texto escrito. Foi solicitado aos alunos que formassem grupos de 03 integrantes e utilizassem os celulares para fotografar cenas da escola. Por exemplo, os estudantes fotografaram professores escrevendo na lousa, alunos estudando ou reunidos na mesa no intervalo e objetos da escola como carteiras lousas e materiais escolares. Um grupo captou a imagem da bandeira da cidade hasteada no pátio tremulando ao vento.

\subsubsection{Aula 06}

A última aula iniciou-se com agradecimento aos alunos pela participação e pela colaboração. Foi pedido a eles que lessem os textos e apresentassem as fotos. Ao todo foram 29 Leads, 27 textos jornalísticos, 10 entrevistas e 29 fotografias. Foi decidido dividir os trabalhos em três murais, sendo o primeiro localizado no pátio e os outros dois localizados no corredor. As atividades foram impressas e coladas nos murais para os alunos das outras classes, funcionários e pais terem acesso aos trabalhos. Ao final, foram esclarecidas algumas dúvidas e apontados os principais acertos e algumas falhas dos alunos. O resultado das atividades realizadas nas últimas 4 aulas foi exposto.

\section{Análise dos Resultados}

Para apresentar o interesse e os resultados dos alunos nas atividades, foram elaborados gráficos que ilustram a participação nas atividades e quantos alunos conseguiram alcançar o objetivo específico da aula. No Figura 3, é apresentada a participação nos debates, podendo perceber que muitos alunos participaram. Na Atividade 1 e na Atividade 2 realizadas na aula 01, dos 28 alunos presentes, apenas 22 participaram dos debates e opinaram sobre o jornalismo e sua função na sociedade. Na Atividade 3, os 29 alunos presentes participaram e elaboraram um Lead, 25 alunos tiveram sucesso e produziram um texto coeso que atendia as regras jornalísticas, entretanto 4 alunos não conseguiram produzir corretamente os seus textos (Figura 4).Na Atividade 4, a atividade foi realizada por 27 alunos, sendo que 21 alunos conseguiram elaborar um texto coeso e seguiram as normas jornalísticas e 6 alunos tiveram dificuldades e não conseguiram atender corretamente a solicitação do professor. Houve 1 aluno que se recusou a participar da atividade e 2 alunos faltaram a aula Figura 5).Na Atividade 5, os alunos foram organizados em 10 grupos dos quais 8 grupos atenderam ao que foi solicitado e 2 grupos entregaram a atividade, porém não atenderam os pré-requisitos de 
VIII Congresso Brasileiro de Informática na Educação (CBIE 2019)

Anais do XXV Workshop de Informática na Escola (WIE 2019)

uma boa entrevista conforme o professor havia explicado em sala de aula (Figura 6).Na Atividade 6, os 29 alunos presentes participaram e tiraram as fotografias conforme o professor havia solicitado.

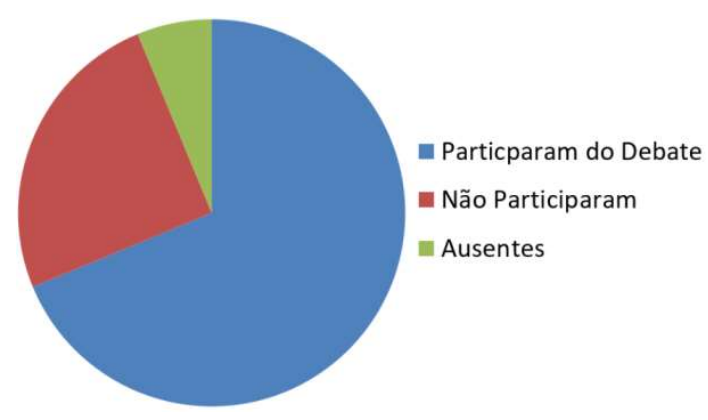

Figura 2-Atividade 1 e Atividade 2 Participação nos Debates

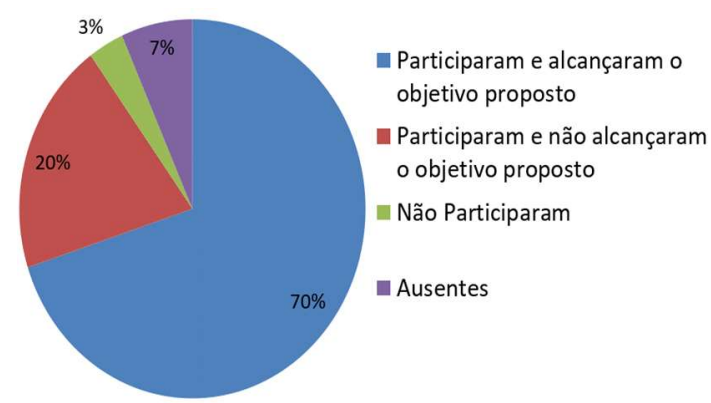

Figura 4-Atividade 4 - Produção de Textos

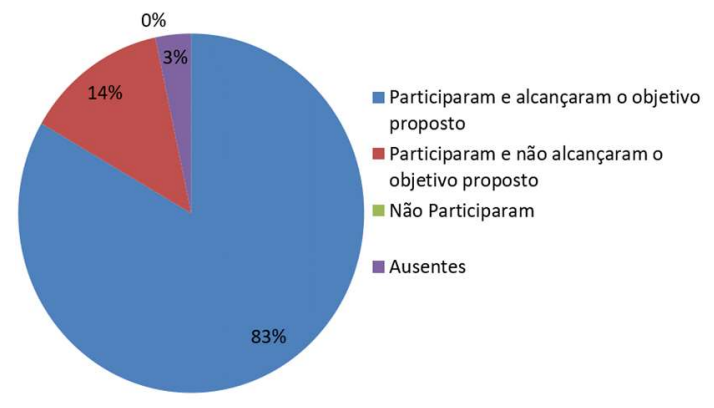

Figura 3-Atividade 3 - Lead

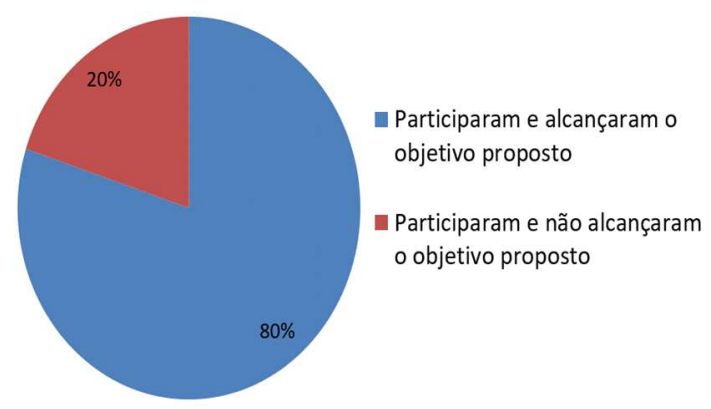

Figura 5-Atividade 5 - Entrevista (grupos)

Após a realização do trabalho, o professor foi entrevistado a respeito da sequência didática aplicada. Segundo ele, a atividade alcançou o objetivo principal que era apresentar o gênero jornalístico aos alunos. Além disso, ele informou que os alunos trabalharam melhor em grupo, produziram e leram mais textos. Para ele, o início dos trabalhos teve participação tímida dos alunos por conta do medo do desconhecido, mas aos poucos os alunos familiarizam-se com o tema e ditaram um novo ritmo às aulas. Questionado a respeito do Sistema Operacional Linux Educacional e seus aplicativos, o professor afirmou que eles são de grande utilidade, são fáceis de utilizar e que, após o contato com esses sistemas de software, os alunos passaram a se interessar mais pelos conteúdos e pela produção de texto. Além disso, o professor afirmou que recomendaria o Linux Educacional e o aplicativo LibreOffice para seus colegas de profissão e que pretende continuar a utilizá-los.

\section{Considerações Finais}

Com a experiência descrita neste artigo e os resultados obtidos pelos alunos em sala de aula na participação e na realização das atividades, foi constatado que a criação do jornal mural incentivou o hábito de leitura e a produção textual dos alunos e os ajudou a reconhecer o gênero informativo. A atividade também fez com que eles trabalhassem melhor em equipe e os aproximou da escola e da comunidade onde vivem. 
VIII Congresso Brasileiro de Informática na Educação (CBIE 2019)

Anais do XXV Workshop de Informática na Escola (WIE 2019)

Com relação a utilização do Linux Educacional ficou constatado a vantagem econômica pois o sistema operacional é gratuito e não onerou despesas à escola, os alunos tiveram facilidade de utilizar o LibreOffice Writer pois este aplicativo tem uma interface semelhante ao Microsoft Word seu concorrente mais conhecido e utilizado. Portanto, pode-se afirmar com base no resultado das atividades realizadas e na experiência retratada que os objetivos propostos foram alcançados.

\section{Referências}

Faria, M. A.; Zanchetta, J. (2002) Para Ler e Fazer o Jornal na Sala de Aula. São Paulo: Contexto.

França, F. (1988) JORNAL MURAL: NOVA E EFICIENTE OPÇÃO. Catálogo Brasileiro de Profissionais de Relações Públicas, São Paulo, v. 10.

Freinet, C. (1974) O jornal escolar. Lisboa: Editorial Estampa.

Freinet, C. (1977) O método natural III - a aprendizagem da escrita. Lisboa: Estampa.

Kleiman, A. (1993) Oficina de leitura. Campinas: Pontes.

Lemos, C. D. (2010) Linux Educacional: desafio para o professor.

Pinto, A., D.; Cybis, W. D. A. (2000). Um estudo teórico sobre as técnicas de avaliação de software educacional. In VI Congreso Argentino de Ciencias de la Computación.

Rossi, C. (2017) O que é jornalismo. Brasiliense.

Signorini, I. (2007). Letramento escolar e formação do professor de língua portuguesa. Linguística Aplicada: suas faces e interfaces. Mercado de Letras: Campinas, 1.

Almeida, J. M.de; Castelano, K. L.; de Souza, C. H. M.; Luquetti, E. C. F. (2015). Uso do blog na escola: recurso didático ou objeto de divulgação?. InterSciencePlace, $1(22)$. 